\title{
Microbial-Induced Carbon Competition in the Spermosphere Leads to Pathogen and Disease Suppression in a Municipal Biosolids Compost
}

\author{
Mei-Hsing Chen and Eric B. Nelson
}

Cornell University, Department of Plant Pathology and Plant-Microbe Biology, 334 Plant Science Building, Ithaca, NY 14853-4203. Current address of M.-H. Chen: Taiwan Agricultural Research Institute, Zhongzheng Rd., No.189, Wufeng Dist., Taichung City 413, Taiwan, Accepted for publication 10 February 2012.

\section{ABSTRACT}

Chen, M.-H., and Nelson, E. B. 2012. Microbial-induced carbon competition in the spermosphere leads to pathogen and disease suppression in a municipal biosolids compost. Phytopathology 102:588-596.

The aim of this study was to understand whether competition for fatty acids in plant seed exudates by compost-derived seed-colonizing microbial communities could explain the suppression of plant infections initiated by sporangia of Pythium ultimum. The germination behavior of $P$. ultimum sporangia in response to cucumber seeds was measured to determine the impact of seed-colonizing microbes on pathogen suppression. Seed-colonizing microbial communities from municipal biosolids compost utilized cucumber seed exudates and linoleic acid in vitro, reducing the respective stimulatory activity of these elicitors to $P$. ultiтит sporangial germination. However, when sporangia were observed directly in the spermosphere of seeds sown in the compost medium, levels of germination and sporangial emptying did not differ from the responses in sand. The percentage of aborted germ tubes was greater after incubating sporangia in compost medium for 12-h than the level of germ tube abortion when sporangia were incubated in sand. Abortion did not occur if previously germinated sporangia were supplemented with cucumber seed exudate. Furthermore, removal of cucumber seed exudate after various stages of germ tube emergence resulted in an increase in aborted germ tubes over time. Adding increasing levels of glucose directly to the compost medium alleviated germ tube abortion in the spermosphere and also eliminated disease suppression. These data fail to support a role for linoleic acid competition in Pythium seedling disease suppression but provide evidence for general carbon competition mediated by seed-colonizing microbial communities as a mechanism for the suppression of Pythium seed infections in municipal biosolids compost.
Compost amendments to soils or container media are effective in reducing the incidence and severity of Pythium-incited plant diseases (44). Although the overall level of disease suppression may be influenced by compost source (2), incorporation rate (53), temperature (1), and target Pythium species $(1,49)$, disease suppression occurs because of the activities of compost-inhabiting microbes (12). For Pythium diseases, disease suppression is expressed through the bacterial communities that colonize seeds and the spermosphere during early stages of plant infection $(7,8,36,47)$. These seed-colonizing communities are dominated by members of the $\alpha-, \beta$-, and $\gamma$-Proteobacteria as well as the Firmicutes and include such taxa as Pseudomonas spp., Enterobacter spp., and Bacillus spp. that are known to be suppressive to Pythium diseases (35). While these bacterial taxa suppress $P$. ultimum directly in the spermosphere, the specific mechanisms involved in pathogen and disease suppression remain unknown.

Numerous mechanisms of disease suppression have been proposed (54). Among the more well-understood mechanisms are those involving the biosynthesis of antimicrobial compounds (46). However, the role that antimicrobial compounds play in the suppression of Pythium infections of seeds is not clear, in part because it is often not known whether the synthesis of antimicrobial compounds by seed-associated microbes is synchronous with the pathogenic development of Pythium in response to seeds. Antimicrobial metabolite production typically occurs during late exponential or early stationary phase within the growth cycle of Gram-negative bacteria (6). On seed surfaces, the lag phase of some bacteria may range from 4 to $12 \mathrm{~h}(16,17)$, making

Corresponding author: E. B. Nelson; E-mail address: ebn1@ cornell.edu

http://dx.doi.org/10.1094/PHYTO-08-11-0241

(c) 2012 The American Phytopathological Society it unlikely that high concentrations of antimicrobial compounds are present in the spermosphere during critical stages of Pythium pathogenic development. Even with seed-associated fungi that produce antimicrobial compounds, $P$. ultimum responds to seeds long before toxic concentrations of these compounds accumulate (23).

Pythium species are particularly sensitive to competitive stresses (37-39) and, in the absence of the carbon inputs to soils from plants, oospores or sporangia typically lyse (22). It has been shown that competitive interactions that restrict the breaking of dormancy of oospores or sporangia are particularly significant for disease initiation $(52,55)$ and survival $(22)$ as well as disease suppression (27-30,32). However, direct experimental evidence for a role for competition between compost-inhabiting microbes and Pythium suppression is very limited $(10,34)$.

In compost-amended soils, much of the indirect evidence for competition in Pythium suppression comes largely from two observations: (i) a decrease in disease severity that correlates with increases in soil microbial activity $(9,10,25,34,49)$, and (ii) a reduction or elimination of disease suppression following carbon supplementation to composts $(10,11,13,34)$. Although such indirect evidence may point to microbial-mediated carbon competition as an important means by which Pythium diseases are suppressed, direct impacts on pathogen development have been rarely documented. More direct evidence for competition between Pythium species and other microbes comes from studies of sporangial and oospore germination in the presence of introduced or indigenous microbes $(10,13,14,16-18,20,36,45,51,52)$. In our previous work with leaf and municipal solid waste composts $(7,8,36)$, we demonstrated that disease suppression is expressed as reduced sporangial germination, seed colonization, and seedling death in the presence of seed-colonizing microbes from composts. Reduced sporangial germination and subsequent infection is 
believed to result from fatty acid competition, which reduces the availability of long-chain unsaturated fatty acids such as oleic and linoleic acids that are essential for the germination of $P$. ultimum sporangia $(36,48,56)$. Oleic and linoleic acids are released early in the seed germination process $(55,56)$ and, with sufficient microbial activity in the spermosphere, could likely serve as limiting resources in competitive interactions (55).

The aim of our study was to examine microbial competition in a municipal solid waste compost to ask whether fatty acid competition or more general carbon competition can explain disease suppression observed previously $(7,8)$. In this work we focus on the behavior of $P$. ultimum sporangia and developing germ tubes during early stages of seed germination since this is one of the most critical stages in disease development (40). The general objectives of our study were to examine various aspects of sporangial behavior (i.e., sporangial germination, sporangial emptying, and germ tube development), both in vitro and in the spermosphere under differing carbon levels to determine a potential role of carbon deprivation in Pythium seedling disease suppression.

\section{MATERIALS AND METHODS}

Production of $\boldsymbol{P}$. ultimum sporangia. Sporangia of $P$. ultimum isolate P4 was maintained on a medium containing soy lecithin as described previously (52) and used as inoculum in all seedling bioassays. Sporangia of isolate P4 only germinate directly by forming germ tubes; zoospores have never been observed in this isolate. After 5 days of mycelial growth at $27^{\circ} \mathrm{C}$, disks $(5-\mathrm{mm}-$ diameter) were excised, placed in sterile petri dishes $(9-\mathrm{cm}-$ diameter) and leached for two consecutive 10-min periods in a buffer ( $\mathrm{pH}$ 5.8) containing $10 \mathrm{mM} \mathrm{Ca}\left(\mathrm{NO}_{3}\right)_{2} \cdot 4 \mathrm{H}_{2} \mathrm{O}, 4 \mathrm{mM}$ $\mathrm{MgSO}_{4} \cdot 7 \mathrm{H}_{2} \mathrm{O}$, and $5 \mathrm{mM} \mathrm{KNO}$. This was followed by a final 3-h leaching period in darkness. The buffer was replaced after each leaching period. After the final leaching period, the leachate was removed, disks were rinsed twice with sterile MilliQ purified water (MQW), and then incubated at $24^{\circ} \mathrm{C}$ in darkness for 2 days. This leaching and incubation treatment led to the lysis of mycelia and promoted the development of sporangia (typically 300 to 700 per disk), leaving only sporangia as inoculum in agar disks. Sporangia produced in this manner mimic the germination responses of those produced on plant tissues where they germinate readily in response to seed exudate and linoleic acid but not to glucose or other simple sugars and amino acids $(36,42)$.

Collection of cucumber seed exudate. Cucumber seeds were sorted by discarding cracked, deformed, or discolored seeds. Seeds were then surface sterilized for $3 \mathrm{~min}$ in $0.05 \%$ sodium hypochlorite with 1 to 2 drops of Tween 20 (polyoxyethylene [20] sorbitan monolaurate) (Sigma-Aldrich, St. Louis, MO) as a wetting agent, rinsed with MQW, and blotted dry. Three grams of seed was added to $30 \mathrm{ml}$ of MQW in 125-ml flasks, and seed exudate was collected by shaking the flasks on a rotary shaker at $150 \mathrm{rpm}$ at $24^{\circ} \mathrm{C}$ for $12 \mathrm{~h}$. Exudate was harvested by decanting the solution through sterile cheesecloth into 50-ml tubes. The antioxidant butylated hydroxytoluene (Sigma-Aldrich) was added to each tube at a final concentration of $10 \mathrm{ppm}$. Ten $10-\mu \mathrm{l}$ aliquots of the exudate solution were spotted onto plates of $10 \%$ Difco potato dextrose agar (Becton-Dickinson, Franklin Lakes, NJ) and $10 \%$ BBL tryptic soy agar (Becton-Dickinson) and assessed for contamination after $48 \mathrm{~h}$. Noncontaminated solutions were pooled, lyophilized, and stored frozen at $-20^{\circ} \mathrm{C}$ under an atmosphere of argon until use.

In vitro degradation of seed exudate and linoleic acid by seed colonizing microbial communities. Seed-associated microbial communities were obtained by vortexing 100 cucumber seeds (previously germinated for $8 \mathrm{~h}$ in compost medium at $-2 \mathrm{kPa}$ and dipped for $1 \mathrm{~s}$ in MQW to remove adhering compost particles) in $20 \mathrm{ml}$ of $0.1 \%$ sodium pyrophosphate (NaPP) solution as described previously (8). Cell suspensions were centrifuged and the microbial pellets were resuspended in $2 \mathrm{ml}$ of $0.1 \% \mathrm{NaPP}$ solution. Cell concentrations were adjusted to $10^{8}$ cells $\mathrm{ml}^{-1}$ at an optical density at $600 \mathrm{~nm}$ and used immediately in experiments. Five hundred microliters of cell suspension was added to $500 \mu \mathrm{l}$ of cucumber seed exudate (resuspended in $1 \% \mathrm{NaPP}$ ) or linoleic acid (sodium linoleate dissolved in Brij 58 [Sigma-Aldrich] [52]) for final concentrations of 5 or $0.3 \mu \mathrm{g} \mu \mathrm{l}^{-1}$ of seed exudates or linoleic acid, respectively. These concentrations were chosen from dose-response experiments to represent concentrations that induce over $90 \%$ sporangial germination. After incubating for $8 \mathrm{~h}$ on a rotary shaker $(150 \mathrm{rpm})$ at $24^{\circ} \mathrm{C}$, the microbially modified solutions were centrifuged for $10 \mathrm{~min}$ at $8,000 \mathrm{rpm}$ and filtered through a $0.2 \mu \mathrm{m}$ filter. Ten microliters of the microbial free supernatant was transferred to each of three replicate agar disks containing P. ultimum sporangia. Exudate and linoleic acid solutions to which no cells were added served as controls. Disks were incubated at $24^{\circ} \mathrm{C}$ for $3 \mathrm{~h}$, sporangia were stained with $0.03 \%$ acid fuchsin in $85 \%$ lactic acid, then observed and each of the following classes of sporangia were enumerated: (i) viable/ germinating sporangia (visible healthy germ tube indicative of infective propagules), (ii) viable nongerminated sporangia (viable and full of cytoplasm but no germ tube visible), (iii) empty nongerminated sporangia (devoid of cytoplasm and nonviable; indicative of direct sporangial lysis or inexplicable cytoplasmic emptying), and (iv) germinated sporangia with aborted germ tubes (germ tube septum visible but distal end of germ tube devoid of cytoplasm indicative of lysis postgermination). Whereas lysis could have been due to autolysis or microbial lysis (31), distinctions between the two were not made. Each of these classes was enumerated at $250 \times$ and/or $400 \times$ by making an optical transect across the entire diameter length of each disk (between 120 and 250 disks were typically counted at $250 \times$ ). There were three disks for each replicate and three replicates for each treatment. The experiment was performed three times.

To determine whether inhibitors of sporangial germination were produced by microbial communities associated with cucumber seeds germinated in compost, we followed a strategy used by van Dijk and Nelson (52) to establish the presence or absence of a sporangial inhibitor without any a priori knowledge of a specific inhibitor molecule. In these experiments, $50 \mu \mathrm{l}$ of the cell free seed exudate or linoleic acid solution that had been previously exposed for $8 \mathrm{~h}$ to seed-colonizing microbial communities was added to $50 \mu \mathrm{l}$ of nontreated seed exudate $\left(10 \mu \mathrm{g} \mu \mathrm{l}^{-1} ; 2 \times\right.$ concentration) or linoleic acid $(0.6 \mu \mathrm{g} / \mu \mathrm{l} ; 2 \times$ concentration $)$. Ten microliters of the 1:1 solution was transferred to each of three agar disks containing P. ultimum sporangia and percent germinated sporangia was determined after 3 -h incubation at $24^{\circ} \mathrm{C}$. Cucumber seed exudate $\left(5 \mu \mathrm{g} \mathrm{l}^{-1} ; 1 \times\right.$ concentration $)$ and linoleic acid $\left(0.3 \mu \mathrm{g} \mu \mathrm{l}^{-1} ; 1 \times\right.$ concentration $)$ were used as positive controls. There were three disks for each replicate and three replicates for each treatment. The experiment was performed three times.

The premise behind this experiment is that if inhibitors are produced by seed-colonizing microbial communities during the first $8 \mathrm{~h}$ of seed germination in compost medium, we would predict that sporangial germination would be reduced, sporangia would be devoid of cytosplasm, or germ tubes would be lysed, even after supplementing microbially modified seed exudate or linoleic acid solutions with nontreated exudate or linoleic acid, respectively. If sporangial germination remains high or sporangia fail to empty or lyse after supplementation, this would serve as evidence that no inhibitors were produced.

Assessment of sporangial germination, sporangial emptying, and germ tube abortion. Bioassays to assess the germination behavior of sporangia in compost were set up as described previously (36). Briefly, fritted glass funnels $(600 \mathrm{ml}, 9-\mathrm{cm}-$ diameter) were packed with $75 \mathrm{~cm}^{3}$ of compost medium ( $\mathrm{pH} \mathrm{7.1)}$ or sterile quartz sand ( $\mathrm{pH} 6.9$; as a nonsuppressive negative control). Five agar disks containing $P$. ultimum sporangia were then 
placed on the surface of the substrate. A single surface-disinfested cucumber seed was then placed directly onto the agar disk. The funnels were then filled with a final $75 \mathrm{~cm}^{3}$ of compost medium or sand. The medium was saturated with MQW and adjusted to a water potential of $-2 \mathrm{kPa}$. After incubation for 4,8 , or $12 \mathrm{~h}$ in compost, five sporangial disks were removed from sand or compost medium, rinsed with MQW, and stained with $0.03 \%$ acid fusion in $85 \%$ lactic acid. Each of the sporangial classes were observed and enumerated as described above. There were five disks in each of three replicate funnels for each treatment. The experiment was performed three times.

Carbon deprivation experiments. These experiments were designed to assess whether the germ tube abortion observed in composts could be induced in vitro by removing carbon and inducing nutrient deprivation conditions. Ten microliters of cucumber seed exudate $\left(5 \mu \mathrm{g} \mathrm{l}^{-1}\right)$ was added to disks containing sporangia of $P$. ultimum. Germinated sporangia were assessed $3 \mathrm{~h}$ after exposure to seed exudate as described above. There were three disks for each replicate and three replicates for each treatment. The experiment was performed three times.

To determine the impact of carbon removal on germ tube development and germ tube abortion, sporangia were exposed to cucumber seed exudate for 1,2 , or $3 \mathrm{~h}$ at $24^{\circ} \mathrm{C}$ to allow for various stages of germ tube development. Germinated sporangia were then washed with MQW to thoroughly remove any seed exudate, treated with $10 \mu \mathrm{l}$ of MQW, and incubated for $1,2,3$, or $4 \mathrm{~h}$. Disks were then stained and examined microscopically at hourly intervals up to $12 \mathrm{~h}$. Again, there were three disks for each replicate and three replicates for each treatment. The experiment was performed three times.

Sporangial germination, germ tube development, and disease suppression in response to glucose supplements to compost. Sporangial germination bioassays were set up as described above. Twelve milliliters of a D-glucose solution was added to the compost medium at concentrations of 25,50 , and $100 \mathrm{mM}$. Compost medium without glucose amendment ( $0 \mathrm{mM}$ glucose) served as a control. After incubation for 4,8 , and $12 \mathrm{~h}$, five sporangial disks were removed from the compost medium, rinsed, stained, and observed for germination, sporangial emptying, and germ tube abortion as described above. There were five disks for each replicate and three replicates for each treatment. The experiment was performed three times.

Seedling bioassays for disease assessment were set up as described previously (8) in fritted glass funnels $(600 \mathrm{ml}, 9-\mathrm{cm}-$ diameter) to maintain constant water potentials. Each funnel was packed with $75 \mathrm{~cm}^{3}$ of compost medium or sand. An agar disk containing $P$. ultimum sporangia was then placed on the surface of the medium. A single surface-disinfested cucumber seed was then placed directly onto the agar disk. The funnels were then filled with a final $75 \mathrm{~cm}^{3}$ of compost medium or sand. The medium was saturated with MQW and adjusted to a water potential of $-2 \mathrm{kPa}$. Noninfested sand and compost medium were used as controls. The entire assembly was incubated at $24^{\circ} \mathrm{C}$ with a $16 \mathrm{~h}$ photoperiod. After 7 days, seedlings were assessed for shoot length. There were three replicates for each treatment, with 10 seedlings per replicate. We used shoot lengths as our measure of disease severity in all experiments because shoot lengths not only reflected observed differences in stand establishment, but they also served as a measure of the stunting that was observed in sand compared with compost medium and also associated with postemergence disease development (8).

Five milliliters of a D-glucose solution was added to each cylinder at concentrations of 25,50 , and $100 \mathrm{mM}$ followed by five agar disks containing $P$. ultimum sporangia. Cylinders without glucose amendment ( $0 \mathrm{mM}$ glucose) served as a control. One surface disinfested cucumber seed was then placed directly onto each filter paper disk. Cylinders were then filled with a final $45 \mathrm{~cm}^{3}$ of sterile sand or compost medium followed by the addition of another $7 \mathrm{ml}$ of 25,50 , or $100 \mathrm{mM}$ glucose solution. MQW (0 mM glucose) and noninoculated sand and compost served as controls. There were 10 seedlings per treatment. The entire assembly was then placed in a clear plastic box and incubated at $24^{\circ} \mathrm{C}$ with a $16 \mathrm{~h}$ photoperiod. Shoot length of each seedling was determined after 7 days of incubation. The experiment was performed three times.

We chose glucose for these experiments in part, because many compost and plant-associated microbes can utilize glucose as a carbon source, but more importantly, because glucose does not directly stimulate the germination of $P$. ultimum sporangia under the conditions of our experiments $(42,43)$. Thus, any increase in disease in the presence of glucose should be a result of changes in germ tube abortion and the subsequent alleviation of disease suppression and not a direct stimulation of $P$. ultimum sporangia.

Statistical analyses. All experiments examining sporangium behavior as a function of either microbial exudate and linoleic acid modification, sporangium age, nutrient removal time, glucose concentrations, or incubation time in compost medium and sand were analyzed by analysis of variance (ANOVA) in a full factorial design using the general linear models procedure within the software package JMP 9.0.2 (SAS Institute, Inc., Cary, NC). For sporangium behavior experiments, percent germinated and empty sporangia as well as sporangia with aborted germ tubes served as main response variables. For experiments in which disease suppression was evaluated in the presence of different glucose concentrations, shoot length served as the main response variable. Where necessary, percentage data were fitted to a normal distribution with homogeneous variances by squaring percentage data prior to ANOVA. The means of significant model effects were separated using Tukey's HSD test at an alpha level of 0.01 . In addition to these analyses, carbon deprivation and glucose supplementation experiments were also analyzed by regression analysis and transformed as appropriate to fit a normal distribution. Mean separations that are presented graphically are based on transformed data. However, the raw data were used to construct the figures, which present results and analyses of one representative experiment.

\section{RESULTS}

Degradation of cucumber seed exudate and linoleic acid by seed-colonizing microbial consortia. Microbes recovered from the surface of cucumber seeds that had germinated in compost for $8 \mathrm{~h}$ (typical seed population levels of 5.7 to $6.3 \mathrm{log}$ cfu per seed) significantly reduced the stimulatory activity of cucumber seed exudate $(P<0.0001)$ and linoleic acid $(P<0.0001)$ to $P$. ultimum sporangial germination compared to seed exudate or linoleic acid that had not been exposed to seed-colonizing microbes (Fig. 1). There were significant microbial effects $(P<0.0001)$, stimulant effects $(P<0.0001)$, and interaction effects $(P<0.0001)$. Microbially modified cell-free solutions supplemented with either nontreated seed exudate or linoleic acid induced significantly $(P<$ $0.01)$ higher levels of sporangial germination than those observed in nonsupplemented microbially modified solutions. None of the sporangia were devoid of cytoplasm in any treatment and no germ tube abortion was observed, even after $12 \mathrm{~h}$ of incubation.

Sporangial germination in sand and compost medium. $P$. ultimum sporangial germination and germ tube development were examined directly in the cucumber spermosphere in sand and compost medium (Fig. 2). In initial experiments, we observed that the level of viable but nongerminated sporangia (no visible germ tubes) never exceeded 3\%. Given this low percentage along with our inability to be certain that these sporangia would not germinate at some point in time, we combined this class of sporangia with those sporangia that were viable and possessed healthy germ tubes. There were significant $(P<0.0001)$ effects of incubation time, substrate (sand or compost medium) and the 
interaction of incubation time and substrate on the number of observed germinated sporangia, empty sporangia, and sporangia with aborted germ tubes. The percentage of viable/healthy germinated sporangia declined significantly $(P<0.01)$ in both the compost medium and sand over $12 \mathrm{~h}$ of incubation (Fig. 3A and B). Although germination percentages were initially quite high, ranging from 85 to $89 \%$, and the percentage of empty sporangia was quite low (11 to $14 \%$ ), the percentage of viable/healthy germinated sporangia declined over time with a corresponding increase in the percentage of empty sporangia and sporangia with aborted germ tubes. In compost, the combined percentage of empty sporangia and sporangia with aborted germ tubes after $12 \mathrm{~h}$ of incubation exceeded the percentage of viable/healthy germinated sporangia (Fig. 3B). Germ tube abortion progressed from the tip of the germ tube back toward the sporangium. The cytoplasm appeared to retract back into the parent sporangium followed by the formation of a septum (Fig. 2).

Carbon deprivation and germ tube abortion. In these experiments, nutrient deprivation only affected the germination of sporangia and germ tube abortion. No significant effects on empty sporangia were observed. Sporangia germinated only in the presence of cucumber seed exudates, and no germination was ever observed in the presence of MQW or in glucose solutions. Nearly $100 \%$ viable/healthy sporangia germinated by $2 \mathrm{~h}$ after the addition of seed exudate and remained at that level up to $4 \mathrm{~h}$. When cucumber seed exudate was removed to impose nutrient deprivation conditions, the percentage of viable/healthy germinated sporangia did not change for the first $3 \mathrm{~h}$ following removal. However, significantly fewer $(P<0.01)$ sporangia with emerged germ tubes were observed by $4 \mathrm{~h}$ after seed exudate removal than those exposed to seed exudate for the entire $4 \mathrm{~h}$ period (Fig. 4). The percentage of empty sporangia following the removal of seed exudate was less than $2 \%$ and did not differ from those where the exudate was present for the entire $4 \mathrm{~h}$ period (data not shown).

Germ tube abortion was evident at all germ tube ages (Fig. 4) and increased positively and significantly with increasing nutrient deprivation times. Regression coefficients for 1-h-old $(y=7.61 x-$ 8.7, $R^{2}=0.893$, slope $P=0.055$, intercept $P=0.231$ ), 2-h-old ( $y=10.3 x-8.7, R^{2}=0.996$, slope $P=0.021$, intercept $P=$ $0.002)$, and 3 -h-old germ tubes $\left(y=4.89 x+12.45, R^{2}=0.917\right.$, intercept $P=0.049$, slope $P=0.042$ ) were all significantly positive. Intercept values were also significant for the 2- and 3-hold germ tubes. Additionally, the mean percentage of sporangia with aborted germ tubes $4 \mathrm{~h}$ after removal of exudate was significantly $(P<0.01)$ lower among 1 -h-old sporangia compared with 2- and 3-h-old sporangia.

Glucose supplementation of compost medium on sporangial germination, germ tube development, and disease suppression. Addition of glucose to the compost medium alleviated pathogen suppression as indicated by the significantly $(P<0.01)$ increased percentages of germinated sporangia ( $\approx 20$ to $60 \%)$ over those in the nonsupplemented compost medium ( $0 \mathrm{mM}$ glucose $)$ (Fig. 5). In the absence of any added glucose, the percentage of viable germinated sporangia was significantly lower $(P<0.01)$ after 8 and $12 \mathrm{~h}$ of incubation in compost medium than after only $4 \mathrm{~h}$ of incubation. In the presence of glucose, germination percentages were near $100 \%$ at all incubation times. The percentage of empty sporangia ranged from 10 to $20 \%$ and did not differ significantly among any of the glucose concentrations or incubation times (data not shown).

Glucose levels and incubation time significantly affected the percentage of sporangia with aborted germ tubes (Fig. 5). In the absence of glucose supplementation, the percentage of aborted germ tubes increased significantly $(P<0.01)$ as the sporangium incubation time in compost increased from 4 to $12 \mathrm{~h}$. Similar results were obtained with sporangia in the presence of $25 \mathrm{mM}$ glucose. The addition of 50 or $100 \mathrm{mM}$ glucose to the compost medium eliminated all germ tube abortion at all incubation times.
Glucose additions to the compost medium also rendered it conducive to Pythium seedling disease (Fig. 6). Shoot lengths of seedlings growing in the compost medium decreased significantly with the addition of increasing concentrations of glucose to the compost $\left(y=-0.4531 x+58.5, R^{2}=0.9244\right.$, slope $\left.P=0.038\right)$. No significant impacts of glucose on cucumber shoot lengths were observed in sand $\left(y=-0.0994 x+8.5, R^{2}=0.5585\right.$, slope $P=$ $0.253)$, in the noninoculated compost $(y=-0.0117 x+83.26$, $R^{2}=0.395$, slope $\left.P=0.801\right)$, or sand $\left(y=-0.1167 x+68.18, R^{2}=\right.$ 0.786 , slope $P=0.113$ ) controls.

\section{DISCUSSION}

The initial goal of our study, which was based largely on our previous observations (36), was to determine whether compostinhabiting microbes that colonized cucumber seeds during early stages of seed germination could prevent $P$. ultimum sporangial germination and subsequent disease development by utilizing linoleic acid present in seed exudates, which serves as the primary sporangial germination stimulant from plant seeds $(55,56)$. Our results have shown clearly that the seed-colonizing microbial community can utilize cucumber seed exudate as well as linoleic acid, rendering each less stimulatory to sporangial germination. However, direct observations of $P$. ultimum sporangial germination adjacent to cucumber seeds in the compost medium failed to show reductions in germination over those in sand. This indicates that, in contrast to earlier observations with cotton in leaf composts (36), competition between P. ultimum sporangia and seed-colonizing microbes for linoleic acid in exudate cannot explain the level of Pythium seedling disease suppression that we observed and that has been observed with introduced spermosphere microbes (52).

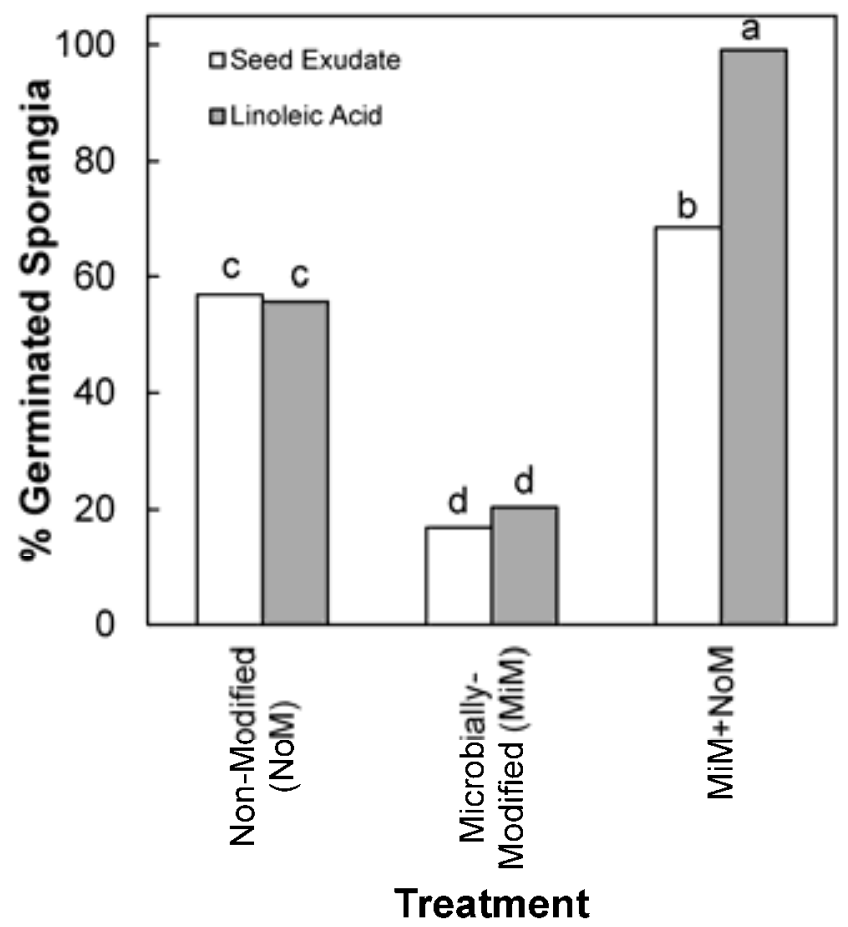

Fig. 1. Germination of Pythium ultimum sporangia in response to cucumber seed exudates or linoleic acid solutions previously exposed to microbial communities recovered from the surface of cucumber seeds germinated in compost for $8 \mathrm{~h}$. Seed exudate or linoleic acid was preincubated for $8 \mathrm{~h}$ with the surface microbial community recovered from cucumber seeds (microbially modified). Aliquots of cell-free stimulants were mixed 1:1 with nontreated cucumber seed exudate or linoleic acid (modified + added stimulant). Nonmicrobially modified solutions (nonmodified) were included as controls. Columns that have different letters are significantly different $(P \leq 0.01)$ according to Tukey's honestly significantly different test. 


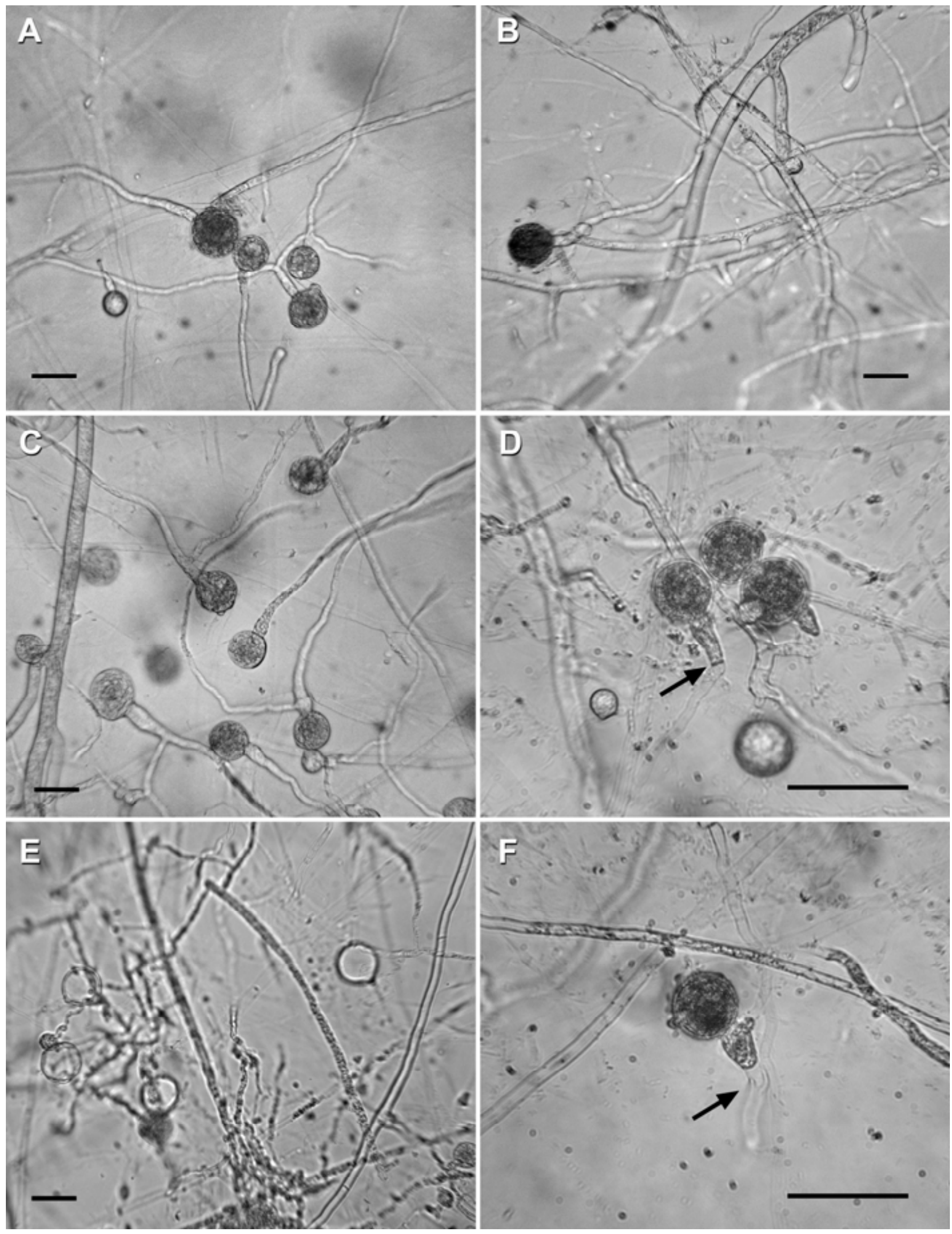

Fig. 2. Germination of Pythium ultimum sporangia in response to cucumber seeds sown in $\mathbf{A}, \mathbf{C}$, and $\mathbf{E}$, sand or $\mathbf{B}$, $\mathbf{D}$, and $\mathbf{F}$, compost medium. Sporangia of $P$. ultimum were germinated $4 \mathrm{~h}$ after incubation in $\mathbf{A}$, sand and $\mathbf{B}$, compost medium. No septa were formed $8 \mathrm{~h}$ after germination in sand $(\mathbf{C})$, whereas retraction of the cytoplasm and the formation of a septum (black arrow) occurred in the compost medium (D). Evacuated sporangia were formed $12 \mathrm{~h}$ after germination in sand $(\mathbf{E})$, whereas germ tubes beyond the septum were lysed (black arrow) in compost $(\mathbf{F})$. Scale bar $=100 \mu \mathrm{m}$. 
Our observations further indicate that, although $P$. ultimum suppression in a municipal biosolids compost is expressed in the cucumber spermosphere (8), it is not expressed as a reduction in germination but rather increased germ tube abortion following germination, pointing to the involvement of microbial activities other than fatty acid degradation and possibly to other microbial species than those previously described in association with cotton seeds germinating in a leaf compost (36). Although our previous work with municipal solid waste composts did not show differences in Pythium seedling disease suppression among several plant species (8), others have demonstrated that microbial communities and activities can vary dramatically among different
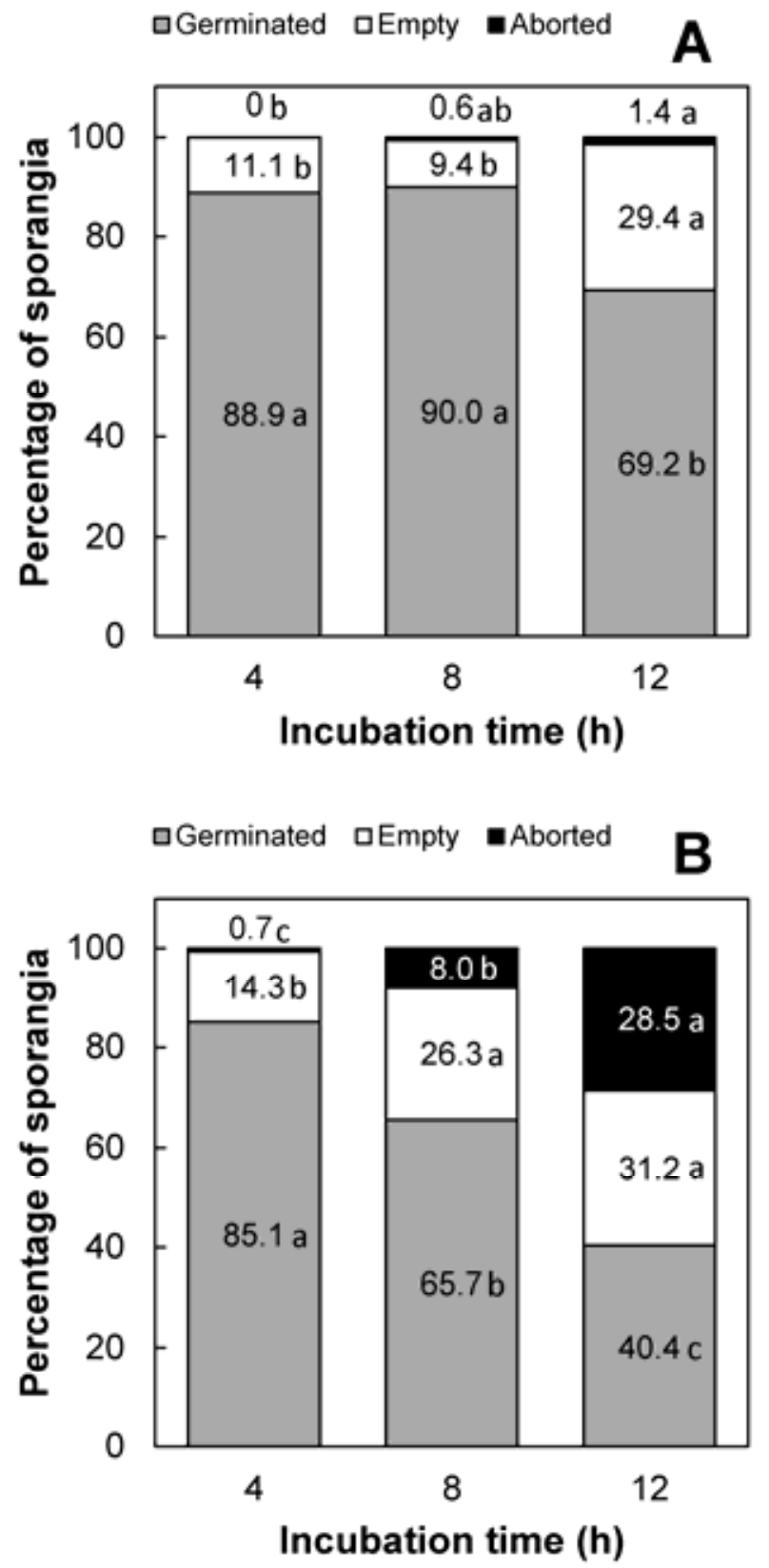

Fig. 3. Percentage of Pythium ultimum sporangia that are either germinated with viable/healthy germ tubes, empty with no cytoplasm, or with aborted germ tubes in response to cucumber seeds sown in $\mathbf{A}$, sand or $\mathbf{B}$, compost medium for 4,8 , or $12 \mathrm{~h}$. Numbers inside the bars represent mean percentages. Percentages followed by the same letter within each sporangium class are significantly different $(P \leq 0.01)$ according to Tukey's honestly significantly different (HSD) test on transformed data. The mean percentages of sporangia with aborted germ tubes were $0.0,0.6$, and 1.4 at 4,8 , and $12 \mathrm{~h}$, respectively. The number at $12 \mathrm{~h}$ was significantly greater $(P \leq 0.01)$ than at $4 \mathrm{~h}$ according to Tukey's HSD test on transformed data. plant species (19), especially within communities of spermosphere microbes $(21,26)$. Thus, we cannot rule out possible plantspecific effects to explain the apparent conflicting observations between the suppression of $P$. ultimum in cucumber and cotton spermospheres. Nor can we rule out possible microbial differences among different composted materials that may impact Pythium seedling disease suppression (1).

One of the more conspicuous observations of $P$. ultimum sporangium behavior in the cucumber spermosphere was the abortion of germ tube development upon prolonged incubation in the municipal biosolids compost. Germ tube abortion was characterized by a retraction of the cytoplasm back into the parent sporangium and the development of a septum between the sporangium and the aborted germ tube. This observation is very similar to that observed previously for $P$. ultimum in a suppressive soil (32) and in a nonsuppressive soil under carbon limiting conditions (45). When sporangia are exposed to carbon-limiting conditions, the cytoplasm retracts from the tip of the germ tube, forming a septum as the cytoplasm moves back into the parent sporangium (45). Under these conditions, germinable secondary sporangia that are smaller than the primary sporangia sometimes form. Yet, in the presence of available soil carbon (provided as either glucose or asparagine supplementation), cytoplasmic retraction and secondary sporangium formation does not occur. It is conceivable that germ tube abortion arising from nutrient deprivation would halt continued pathogenic development of $P$. ultimum and prevent seedling infections. This led us to ask whether such a time-dependent nutrient deprivation might occur in the cucumber spermosphere and thus explain germ tube abortion and subsequent disease suppression in the compost medium.

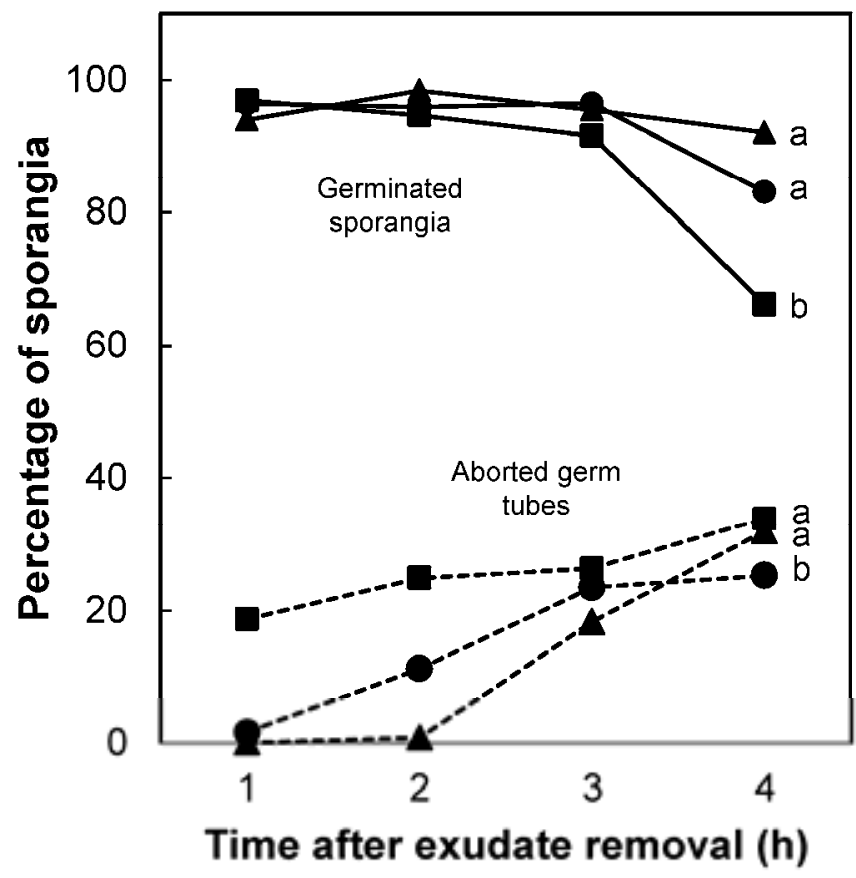

Fig. 4. Germinated Pythium ultimum sporangia (solid lines) and sporangia with aborted germ tube development (dashed lines) as a function of germ tube age and nutrient deprivation time. Sporangia were germinated in seed exudates to produce germ tubes of 1 (triangles), 2 (circles), or 3 (squares) h of age, at which time seed exudates were removed to induce nutrient deprivation conditions. Germinated sporangia in each age class were incubated for 1, 2, 3, or $4 \mathrm{~h}$ after seed exudate removal. Different letters following data points for germinated sporangia and sporangia with aborted germ tubes at $4 \mathrm{~h}$ after exudate removal represent significant differences $(P \leq 0.01)$ according to Tukey's honestly significantly different test on transformed data. Regression equations for germ tube age classes are as follows: 1-h-old germ tubes $(y=$ $7.61 x-8.7, R^{2}=0.893$, slope $\left.P=0.055\right), 2$-h-old germ tubes $(y=10.3 x-8.7$, $R^{2}=0.996$, slope $\left.P=0.021\right)$, and 3 -h-old germ tubes $\left(y=4.89 x+12.45, R^{2}=\right.$ 0.917 , intercept $P=0.049$ ). 
For nutrient competition to occur between two or more microbial species, a common resource must be limiting $(15,33)$. Although compost $(3,4)$ and spermosphere microbial communities (5) are able to utilize a wide range of carbon compounds, those that serve as limiting resources are unknown. We focused our nutrient deprivation studies on glucose because nearly all heterotrophic organisms can utilize this simple sugar, making it likely that such a compound would be limiting in a compost where microbial activity is high. The hypothesis that sugars may be limiting is further supported by the observation that sugars are commonly found at relatively low levels in cucumber spermospheres (56) and that concentrations of glucose and other carbohydrates are more available in suppressive than in some conducive composts (10).

Based on our nutrient deprivation experiments with both seed exudate and glucose, we conclude that general carbon deprivation can explain Pythium seedling disease suppression in our municipal biosolids compost. For example, adding increasing concentrations of glucose to the municipal biosolids compost negated Pythium seedling disease suppression. We attribute this to the alleviation of microbial carbon competition since glucose does not enhance $P$. ultimum development by stimulating germination or seed colonization when produced under the conditions of our experiments (41-43). Similar alleviation of carbon competition has been observed in other Pythium suppressive composts (34) where glucose supplementation was shown to not only eliminate suppressiveness but delay germ tube and hyphal lysis of Pythium aphanidermatum. In other composts, Pythium seedling disease suppression on cucumber is related to low available glucose and other carbohydrates that support germ tube development (9).

Direct observations of germ tube abortion among sporangia that had germinated in the municipal biosolids composts provides additional evidence to support our conclusion that Pythium seedling disease suppression is due to nutrient deprivation. Increased germ tube abortion and subsequent lysis is commonly induced by nutrient depletion (34). This commonly represents an autolytic phenomenon that does not involve inhibitors produced by other microbes (31). It is therefore unlikely that the germ tube

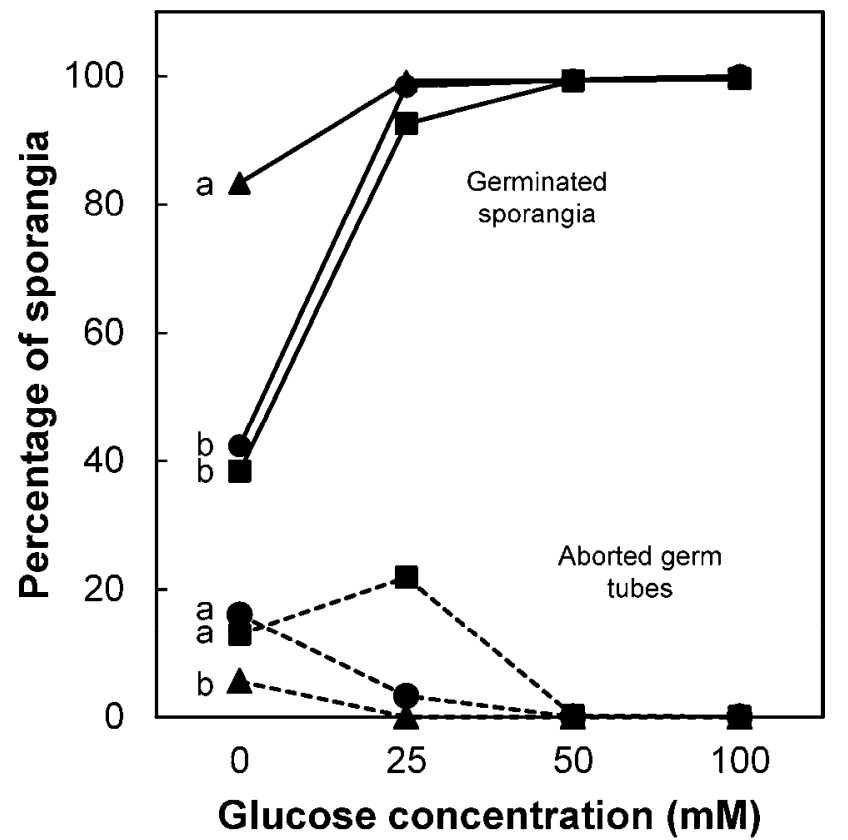

Fig. 5. Sporangium germination (solid lines) and aborted germ tube development (dashed lines) of Pythium ultimum incubated for 4 (triangles), 8 (circles), or 12 (squares) $\mathrm{h}$ in compost medium amended with different glucose concentrations. Different letters following data points represent significant differences $(P \leq 0.01)$ according to Tukey's honestly significantly different test on transformed data. abortion we observed is due to the biosynthesis of inhibitors such as antibiotics by seed colonizing microbes but rather due directly to the nutrient deplete conditions. This is further supported by the observation that, in the presence of nutrient-rich conditions (i.e., cucumber seed exudate or glucose supplementation), germ tube abortion was prevented. These observations are similar to those of Stanghellini and Hancock (50) who found that germ tube growth of $P$. ultimum ceased within 2.5 to $3 \mathrm{~h}$ under nutrient limiting conditions whereas germ tubes maintained high growth rates for extended periods of time under conditions of high carbon availability. Carbon availability in a disease-suppressive spermosphere would be expected to decrease with time because of the high levels of microbial activity, but also because exudation from seeds declines as water imbibition slows (40). Therefore, the longer that germinated sporangia reside in a disease-suppressive spermosphere, the more limiting carbon should become. If the carbon is replaced, germ tubes should not abort and disease development would proceed (i.e., suppression would be eliminated). Our observations are consistent with this model.

Although our results establish strong associations between carbon availability, germ tube abortion, and Pythium seedling disease suppression, these findings are not entirely definitive. Little is known of the spermosphere resources utilized by $P$. ultimum after germ tube emergence. Much of our understanding of $P$. ultimum metabolism comes from studies of molecules that initiate sporangial germination (40). Knowledge of postgermination metabolic activities will be essential to confirming observations in this study of competitive interactions with seed-colonizing microbes. Earlier substrate utilization studies of spermosphere microbial communities provide some insight into the metabolic profiles of seed-colonizing microbial communities (5). However, the similarities of metabolic profiles of compost microbes relative to soil microbes are unknown.

It is possible that other microbial interactions can explain the suppression observed with our municipal biosolids compost. The traditional explanations for microbial suppression of pathogens include competitive interactions, parasitic interactions, amensalistic interactions, and induced plant resistance (54). It is unlikely,

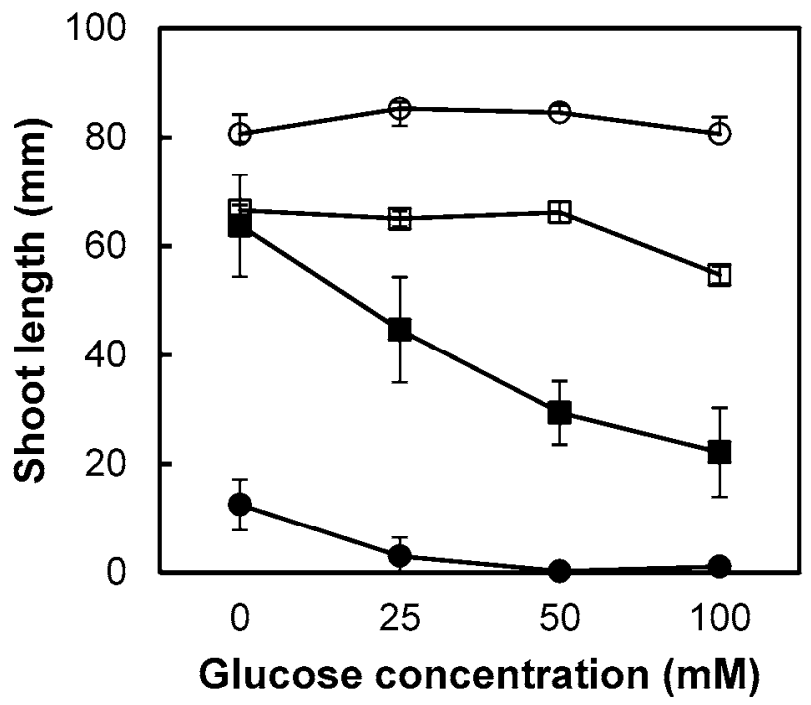

Fig. 6. Relationships between Pythium seedling disease suppression (as measured by shoot length) of cucumber in compost (noninoculated = open squares; inoculated $=$ closed squares) or sand (noninoculated $=$ open circles; inoculated $=$ closed circles) treated with different concentrations of glucose . Shoot lengths were determined 7 days after planting. Regression equations for each treatment are as follows: inoculated compost medium $(y=-0.4531 x+$ $58.5, R^{2}=0.9244$, slope $\left.P=0.038\right)$, inoculated sand $\left(y=-0.0994 x+8.5, R^{2}=\right.$ 0.5585 , slope $P=0.253)$, noninoculated compost medium $(y=-0.0117 x+$ $83.26, R^{2}=0.395$, slope $\left.P=0.801\right)$, and noninoculated sand $(y=-0.1167 x+$ $68.18, R^{2}=0.786$, slope $P=0.113$ ). 
however, that parasitic interactions are involved in Pythium seedling disease suppression because direct observations of germinating sporangia up to $12 \mathrm{~h}$ reveal no evidence of fungal, oomycete, or bacterial parasites. Furthermore, although germ tube lysis often represents an autolytic phenomenon resulting from nutrient depletion (34), such lysis is also known to occur as a result of inhibitors produced by other microbes (31). Such an inhibitorinduced lysis is unlikely for a couple of reasons. First, the metabolism of cucumber seed exudate by seed colonizing bacteria did not reveal the presence of any inhibitors produced within the first $8 \mathrm{~h}$ of seed germination. If inhibitors are produced in the spermosphere, seed exudate would support such a biosynthesis. Second, in other studies involving the seed-colonizing bacterium Pseudomonas fluorescens, the transcription of biosynthetic genes for the inhibitor, oomycin A was not observed on seed surfaces until 10 to $12 \mathrm{~h}$ after seeds were sown (24). Therefore, if amensalistic interactions were to occur, they would likely occur beyond $12 \mathrm{~h}$ and at a stage of pathogenesis unlikely to have much impact on overall disease severity (55). Finally, induced resistance in cucumber is unlikely within the time frame studied since the bulk of the interactions we describe in this paper take place at times before radicles emerge. Therefore, we believe that the competitive interactions that lead to nutrient deprivation and the subsequent abortion of $P$. ultimum germ tubes described above can explain the suppression of Pythium seedling disease observed in our study.

\section{ACKNOWLEDGMENTS}

This work was supported by a fellowship awarded to M.-H. Chen by the Taiwan Ministry of Education and by Research Grant IS-3512-04 from BARD, the United States-Israel Binational Agricultural Research and Development Fund. We thank M. A. Karp for technical assistance.

\section{LITERATURE CITED}

1. Ben-Yephet, Y., and Nelson, E. B. 1999. Differential suppression of cucumber damping-off caused by Pythium aphanidermatum, $P$. irregulare, and $P$. myriotylum in composts at different temperatures. Plant Dis. 83:356-360.

2. Bonanomi, G., Antignani, V., Capodilupo, M., and Scala, F. 2010. Identifying the characteristics of organic soil amendments that suppress soilborne plant diseases. Soil Biol. Biochem. 42:136-144.

3. Borrero, C., Ordovas, J., Trillas, M. I., and Aviles, M. 2006. Tomato Fusarium wilt suppressiveness: The relationship between the organic plant growth media and their microbial communities as characterised by Biolog (R). Soil Biol. Biochem. 38:1631-1637.

4. Borrero, C., Trillas, M. I., Ordovas, J., Tello, J. C., and Aviles, M. 2004. Predictive factors for the suppression of Fusarium wilt of tomato in plant growth media. Phytopathology 94:1094-1101.

5. Buyer, J. S., Roberts, D. P., and Russek-Cohen, E. 1999. Microbial community structure and function in the spermosphere as affected by soil and seed type. Can. J. Microbiol. 45:138-144.

6. Chater, K. F., and Bibb, M. J. 2008. Regulation of bacterial antibiotic production. Pages 57-105 in: Biotechnology Set. Wiley-VCH Verlag $\mathrm{GmbH}$, Germany.

7. Chen, M.-H., Jack, A. H., McGuire, I. C., and Nelson, E. B. 2012. Seedcolonizing bacterial communities associated with the suppression of Pythium seedling disease in a municipal biosolids compost. Phytopathology 102:478-489.

8. Chen, M.-H., and Nelson, E. B. 2008. Seed-colonizing microbes from municipal biosolids compost suppress Pythium ultimum damping-off on different plant species. Phytopathology 98:1012-1018.

9. Chen, W., Hoitink, H. A. J., and Madden, L. V. 1988. Microbial activity and biomass in container media for predicting suppressiveness to damping-off caused by Pythium ultimum. Phytopathology 78:1447-1450.

10. Chen, W., Hoitink, H. A. J., Schmitthenner, A. F., and Tuovinen, O. H. 1988. The role of microbial activity in suppression of damping-off caused by Pythium ultimum. Phytopathology 78:314-322.

11. de Boer, W., Verheggen, P., Gunnewiek, P., Kowalchuk, G. A., and van Veen, J. A. 2003. Microbial community composition affects soil fungistasis. Appl. Environ. Microbiol. 69:835-844.

12. De Ceuster, T. J. J., and Hoitink, H. A. J. 1999. Prospects for composts and biocontrol agents as substitutes for methyl bromide in biological control of plant diseases. Compost Sci. Util. 7:6-15.

13. Elad, Y., and Chet, I. 1987. Possible role of competition for nutrients in biocontrol of Pythium damping-off by bacteria. Phytopathology 77:190195.

14. Ellis, R. J., Timms-Wilson, T. M., Beringer, J. E., Rhodes, D., Renwick, A., Stevenson, L., and Bailey, M. J. 1999. Ecological basis for biocontrol of damping-off disease by Pseudomonas fluorescens 54/96. J. Appl. Microbiol. 87:454-463.

15. Fredrickson, A. G., and Stephanopoulos, G. 1981. Microbial competition. Science 213:972-979.

16. Fukui, R., Poinar, E. I., Bauer, P. H., Schroth, M. N., Hendson, M., Wang, X. L., and Hancock, J. G. 1994. Spatial colonization patterns and interaction of bacteria on inoculated sugar beet seed. Phytopathology 84:1338-1345.

17. Fukui, R., Schroth, M. N., Hendson, M., and Hancock, J. G. 1994. Interaction between strains of pseudomonads in sugar beet spermospheres and their relationship to pericarp colonization by Pythium ultimum in soil. Phytopathology 84:1322-1330.

18. Fukui, R., Schroth, M. N., Hendson, M., Hancock, J. G., and Firestone, M. K. 1994. Growth patterns and metabolic activity of pseudomonads in sugar beet spermospheres: Relationship to pericarp colonization by Pythium ultimum. Phytopathology 84:1331-1338.

19. Garbeva, P., van Veen, J. A., and van Elsas, J. D. 2004. Microbial diversity in soil: Selection of microbial populations by plant and soil type and implications for disease suppressiveness. Annu. Rev. Phytopathol. 42:243270.

20. Green, H., Heiberg, N., Lejbolle, K., and Jensen, D. F. 2001. The use of a GUS transformant of Trichoderma harzianum, strain T3a, to study metabolic activity in the spermosphere and rhizosphere related to biocontrol of Pythium damping-off and root rot. Eur. J. Plant Pathol. 107:349-359.

21. Green, S. J., Michel, F. C., Hadar, Y., and Minz, D. 2007. Contrasting patterns of seed and root colonization by bacteria from the genus Chryseobacterium and from the family Oxalobacteraceae. ISME J. 1:291299.

22. Hancock, J. G. 1981. Longevity of Pythium ultimum in moist soils. Phytopathology 71:1033-1037.

23. Harris, A. R., and Lumsden, R. D. 1997. Interactions of Gliocladium virens with Rhizoctonia solani and Pythium ultimum in non-sterile potting medium. Biocon. Sci. Technol. 7:37-47.

24. Howie, W. J., and Suslow, T. V. 1991. Role of antibiotic biosynthesis in the inhibition of Pythium ultimum in the cotton spermosphere and rhizosphere by Pseudomonas fluorescens. Mol. Plant-Microbe Interact. 4:393-399.

25. Inbar, Y., Boehm, M. J., and Hoitink, H. A. J. 1991. Hydrolysis of fluorescein diacetate in sphagnum peat container media for predicting suppressiveness to damping-off caused by Pythium ultimum. Soil Biol. Biochem. 23:479-483.

26. Kageyama, K., and Nelson, E. B. 2003. Differential inactivation of seed exudate stimulation of Pythium ultimum sporangium germination by Enterobacter cloacae influences biological control efficacy on different plant species. Appl. Environ. Microbiol. 69:1114-1120.

27. Kao, C. W., and Ko, W. H. 1983. Nature of suppression of Pythium splendens in a pasture soil in South Kohala, Hawaii. Phytopathology 73:1284-1289.

28. Kao, C. W., and Ko, W. H. 1986. The role of calcium and microorganisms in suppression of cucumber damping-off caused by Pythium splendens in a Hawaiian soil. Phytopathology 76:221-225.

29. Kao, C. W., and Ko, W. H. 1986. Suppression of Pythium splendens in a Hawaiian soil by calcium and microorganisms. Phytopathology 76:215220.

30. Ko, W. H., and Ho, W. C. 1983. Screening soils for suppressiveness to Rhizoctonia solani and Pythium splendens. Ann. Phytopathol. Soc. Japan 49:1-9.

31. Ko, W. H., and Lockwood, J. L. 1970. Mechanism of lysis of fungal mycelia in soil. Phytopathology 60:148-154.

32. Lifshitz, R., and Sneh, B. 1984. Soil suppressiveness to a plant pathogenic Pythium species. Phytopathology 74:1054-1061.

33. Lockwood, J. L. 1981. Exploitation competition. Pages 319-349 in: The Fungal Community, Its Organization and Role in the Ecosystem. D. T. Wicklow and G. C. Carroll, eds. Marcel Dekker, Inc., New York.

34. Mandelbaum, R., and Hadar, Y. 1990. Effects of available carbon source on microbial activity and suppression of Pythium aphanidermatum in compost and peat container media. Phytopathology 80:794-804.

35. Martin, F. N., and Loper, J. E. 1999. Soilborne plant diseases caused by Pythium spp.: Ecology, epidemiology, and prospects for biological control. Crit. Rev. Plant Sci. 18:111-181.

36. McKellar, M. E., and Nelson, E. B. 2003. Compost-induced suppression of Pythium damping-off is mediated by fatty-acid-metabolizing seedcolonizing microbial communities. Appl. Environ. Microbiol. 69:452-460. 
37. Mondal, S. N., and Hyakumachi, M. 2000. Soil factors affecting carbon loss and pathogenicity of oospores of Pythium aphanidermatum. Soil Biol. Biochem. 32:111-118.

38. Mondal, S. N., Kageyama, K., and Hyakumachi, M. 1995. Influence of soil matric potential on the debilitation of oospores of Pythium aphanidermatum. Soil Biol. Biochem. 27:1319-1324.

39. Mondal, S. N., Kageyama, K., and Hyakumachi, M. 1996. Decreased germinability and virulence of oospores of Pythium aphanidermatum in relation to loss of endogenous carbon during incubation in soil. Soil Biol. Biochem. 28:545-553.

40. Nelson, E. B. 2004. Microbial dynamics and interactions in the spermosphere. Annu. Rev. Phytopathol. 42:271-309.

41. Nelson, E. B., Chao, W. L., Norton, J. M., Nash, G. T., and Harman, G. E. 1986. Attachment of Enterobacter cloacae to hyphae of Pythium ultimum: Possible role in biological control of Pythium pre-emergence dampingoff. Phytopathology 76:327-335.

42. Nelson, E. B., and Craft, C. M. 1989. Comparative germination of culture-produced and plant-produced sporangia of Pythium ultimum in response to soluble seed exudates and exudate components. Phytopathology 79:1009-1013.

43. Nelson, E. B., and Hsu, J. S. T. 1994. Nutritional factors affecting responses of sporangia of Pythium ultimum to germination stimulants. Phytopathology 84:677-683.

44. Noble, R., and Coventry, E. 2005. Suppression of soil-borne plant diseases with composts: A review. Biocont. Sci. Technol. 15:3-20.

45. Paulitz, T. C., and Baker, R. 1988. The formation of secondary sporangia by Pythium ultimum: The influence of organic amendments and Pythium nunn. Soil Biol. Biochem. 20:151-156.

46. Raaijmakers, J. M., Vlami, M., and de Souza, J. T. 2002. Antibiotic production by bacterial biocontrol agents. Antonie Van Leeuwenhoek 81:537-547.

47. Rotenberg, D., Wells, A. J., Chapman, E. J., Whitfield, A. E., Goodman, R. M., and Cooperband, L. R. 2007. Soil properties associated with organic matter-mediated suppression of bean root rot in field soil amended with fresh and composted paper mill residuals. Soil Biol. Biochem. 39:2936-2948.

48. Ruttledge, T. R., and Nelson, E. B. 1997. Extracted fatty acids from Gossypium hirsutum stimulatory to the seed-rotting fungus, Pythium ultimum. Phytochemistry 46:77-82.

49. Scheuerell, S. J., Sullivan, D. M., and Mahaffee, W. F. 2005. Suppression of seedling damping-off caused by Pythium ultimum, $P$ irregulare, and Rhizoctonia solani in container media amended with a diverse range of Pacific northwest compost sources. Phytopathology 95:306-315.

50. Stanghellini, M. E., and Hancock, J. G. 1971. The sporangium of Pythium ultimum as a survival structure in soil. Phytopathology 61:157-164.

51. van Dijk, K., and Nelson, E. B. 1998. Inactivation of seed exudate stimulants of Pythium ultimum sporangium germination by biocontrol strains of Enterobacter cloacae and other seed-associated bacteria. Soil Biol. Biochem. 30:183-192.

52. van Dijk, K., and Nelson, E. B. 2000. Fatty acid competition as a mechanism by which Enterobacter cloacae suppresses Pythium ultimum sporangium germination and damping-off. Appl. Environ. Microbiol. 66:5340-5347.

53. Veeken, A. H. M., Blok, W. J., Curci, F., Coenen, G. C. M., Termorshuizen, A. J., and Hamelers, H. V. M. 2005. Improving quality of composted biowaste to enhance disease suppressiveness of compostamended, peat-based potting mixes. Soil Biol. Biochem. 37:2131-2140.

54. Whipps, J. M. 2001. Microbial interactions and biocontrol in the rhizosphere. J. Exp. Bot. 52:487-511.

55. Windstam, S., and Nelson, E. B. 2008. Differential interference with Pythium ultimum sporangial activation and germination by Enterobacter cloacae in the corn and cucumber spermospheres. Appl. Environ. Microbiol. 74:4285-4291.

56. Windstam, S., and Nelson, E. B. 2008. Temporal release of fatty acids and sugars in the spermosphere: Impacts on Enterobacter cloacae-induced biological control. Appl. Environ. Microbiol. 74:4292-4299. 